\title{
Identification of Plasmopara viticola Genes Potentially Involved in Pathogenesis on Grapevine Suggests New Similarities Between Oomycetes and True Fungi
}

\author{
P. Luis, A. Gauthier, S. Trouvelot, B. Poinssot, and P. Frettinger
}

First author: Université Lyon 1, UMR CNRS 5557, USC INRA 1364, Ecologie Microbienne, 43 boulevard du 11 Novembre 1918 , F-69622 Villeurbanne Cedex, France; and second, third, fourth, and fifth authors: Université de Bourgogne, UMR 1347 Agroécologie, 17 rue Sully, BP 86510, F-21000 Dijon, France.

Current address of A. Gauthier: Division of Plant Biology, Department of Biosciences, P.O. Box 65, Fi-00014 University of Helsinki, Finland.

Accepted for publication 22 April 2013.

\begin{abstract}
Luis, P., Gauthier, A., Trouvelot, S., Poinssot, B., and Frettinger, P. 2013. Identification of Plasmopara viticola genes potentially involved in pathogenesis on grapevine suggests new similarities between oomycetes and true fungi. Phytopathology 103:1035-1044.

Plant diseases caused by fungi and oomycetes result in significant economic losses every year. Although phylogenetically distant, these organisms share many common features during infection. We identified genes in the oomycete Plasmopara viticola that are potentially involved in pathogenesis in grapevine by using fungal databases and degenerate primers. Fragments of $P$. viticola genes encoding NADH-ubiquinone oxidoreductase $(P v N u o)$, laccase $(P v L a c)$, and invertase $(P v I n v)$ were obtained. $P v N u o$ was overexpressed at 2 days postinoculation (dpi), dur-

ing the development of the first hyphal structures and haustoria. PvLac was overexpressed at $5 \mathrm{dpi}$ when genes related to pterostilbene biosynthesis were induced in grapevine. Transcript level for PvInv increased between 1 and 4 dpi before reaching a plateau. These results might suggest a finely tuned strategy of infection depending on nutrition and plant response. Phylogenetic analyses of $P v N u o$ showed that $P$. viticola clustered with other oomycetes and was associated with brown algae and diatoms, forming a typical Straminipila clade. Based on the comparison of available sequences for laccases and invertases, the group formed by $P$. viticola and other oomycetes tended to be more closely related to Opisthokonta than to Straminipila. Convergent evolution or horizontal gene transfer could explain the presence of fungus-like genes in P. viticola.
\end{abstract}

Fungi and oomycetes cause plant diseases that result in significant economic losses in agricultural and horticultural industries every year. Although phylogenetically distant, both types of organisms share many common features in their infection processes. Oomycetes and fungi use specialized infection structures including appressoria, infection hyphae, and haustoria. Glycoproteins, lipids, and polysaccharides are the main molecular compounds used by fungal spores for host surface attachment (54). Glycoproteins and $\beta$-1,3-glucans present in the adhesive layer are secreted by germinating sporangia of the oomycete Hyaloperonospora brassicae to improve germling attachment (9). Osmotrophic microorganisms, such as fungi and oomycetes, secrete enzymes into the external environment to degrade polymers such as cellulose, lipids, proteins, and lignin. The resulting simple sugars, amino acids, and fatty acids are transported into the growing cell and metabolized (50). Even if the amount of cell-walldegrading enzymes is reduced in obligate biotrophic oomycetes and their role in the nutrition is limited (5), both fungi and oomycetes use cell-wall-degrading enzymes to invade plant tissues $(24,52)$. These similarities may be explained by the fact that phytopathogenic fungi and oomycetes are exposed to very similar plant defense mechanisms, mainly independent of phylogenetic origin but, rather, dependent on mode of infection. Thus, a plant will adapt its response to biotrophic and necrotrophic microbes with salicylate- or jasmonate-mediated mechanisms, respectively

Corresponding author: P. Frettinger; E-mail address: frettinger@yahoo.fr

http://dx.doi.org/10.1094/PHYTO-06-12-0121-R

(c) 2013 The American Phytopathological Society
(23). The genetic basis of common infection mechanisms is not yet clear, although common Gene Ontology terminology has been established between fungi and oomycetes (35).

The fact that oomycetes and fungi are able to cope with the same plant defenses or nutrient availabilities through similar mechanisms is fascinating because these organisms are not phylogenetically closely related. Oomycetes are taxonomically grouped among the nonphotosynthetic Straminipila and are closely related to the photosynthetic Straminipila, which includes diatoms and brown algae. Although other photosynthetic algae (i.e., red and green algae) and land plants are members within the Archaeplastida, fungi belong to the Opisthokonta. In the kingdom Fungi, ascomycetes and basidiomycetes are two major phyla (3).

Grapevine (Vitis vinifera L.), a major fruit crop worldwide, is affected by many diseases. One of the most notorious pathogens is Plasmopara viticola, the obligate biotrophic oomycete known to cause downy mildew. Grapevine defense mechanisms are largely studied with respect to decreasing the need for chemical treatments, which are not compatible with a modern sustainable viticulture $(14,29)$. Thus, grapevine defenses triggered in response to pathogen attack and elicitors (pathogen- and mitogen-associated molecular patterns) have been studied in more detail $(2,16$, 53). In these studies, pathogen infection structures and hyphal development in plant tissues are well documented, mainly at a microscopic level. However, there are fewer specific investigations of the mechanisms of attack by pathogens themselves. To our knowledge, the pioneering work of Werner et al. (56) is the only study describing genes of $P$. viticola associated with two key steps of leaf infection. In this study, two chitin synthase genes ( $P v C H S 1$ and $P v C H S 2$ ) were identified based on their similarities 
with true fungi, and their expression levels were followed during the leaf infection process. PvCHSI was expressed in leaves with oil-fleck disease symptoms, corresponding to extended intercellular hyphal growth, whereas $P v C H S 2$ was specifically expressed in the sporangia, corresponding to the disseminating phase of the infection. Both of these genes may relate to the significant morphological changes occurring during pathogenic development and asexual reproduction (56). Later, cDNA amplified fragment length polymorphism was used to identify grapevine and $P$. viticola genes expressed in a fully infected leaf (39), and Blum et al. (7) described four cellulose synthases potentially involved in pathogenesis.

Fully sequenced genomes of plants and their associated pathogens $(17,27)$, and the availability of mutants, give a strong molecular basis to the study of pathosystems (58), making it timely to investigate plant-pathogen interactions to advance our knowledge of phytopathology. Using whole-genome and gene-bygene phylogenetic analysis, Richards et al. (41) demonstrated an extensive pattern of cross-kingdom horizontal gene transfer (HGT) between fungi and oomycetes. A large fraction of these fungal HGT-derived proteins were predicted to be involved in the breakdown of plant cell walls and in the acquisition of environmental nutrients such as sugars without any in planta investigation. Because such transfers were not observed in animal parasites or free-living oomycete species, these data strongly suggest that HGT from fungi has played a significant role in the evolution of oomycetes to successful plant parasites (41). Concerning $P$. viticola, the genetic and molecular mechanisms underlying infection have not yet been identified. Whole-genome sequencing and comparative genomic analysis were not performed on $P$. viticola because no isolated strain is available for this obligate biotrophic oomycete. However, as for others plant-parasitic oomycetes, multiple acquisitions of genes from fungi might also occur in this species. Based on fungal databases and using degenerate primers, the present study has been able to identify three $P$. viticola genes potentially involved in grapevine tissue colonization. We selected three key elements needed for a successful colonization: (i) the ability to produce energy from the encysted zoospore before acquiring nutrients from the host, (ii) the capacity to express genes encoding detoxifying enzymes, and (iii) the ability to get nutrients from the host plant. We were able to obtain fragments of $P$. viticola genes encoding proteins involved in these three steps: NADH-ubiquinone oxidoreductase, laccase, and invertase, respectively. NADH-ubiquinone oxidoreductase is involved in electron transfer in mitochondrion and plays an essential role during the spreading in plant tissue such as root colonization by Pseudomonas fluorescens $(8,12)$. In the same way, Fusarium graminearum with a mutated NADH-ubiquinone oxidoreductase exhibits reduced virulence on corn silks and wheat heads (48). Curcumin, a natural plant polyphenol preventing hyphae development, induces reactive oxygen species and NADH-ubiquinone oxidoreductase expression in Candida albicans (49). Finally, NADH-ubiquinone oxidoreductase seems to be a key detoxifying element of Aspergillus nidulans resistance to plant antifungal compounds such as farnesol and its related isoprenoids, produced in fruit and vegetables (15).

Of the enzymes secreted into the external environment that are able to degrade polymers, we first investigated laccase. Laccases form a group of enzymes known as copper oxidases, characterized by four cupric $\left(\mathrm{Cu}^{2+}\right)$ ions (4). Fungal laccases have been implicated in fungal pathogenicity $(11,22,34,43)$. Laccases are able to degrade phenolic compounds such as lignin or caffeic and ferulic acids, which appear to be among the most important physical and chemical weapons, respectively, of plants (4). We subsequently investigated an enzyme able to release simple sugars, which can be assimilated by a pathogen. Invertases are plant or fungal enzymes catalyzing the degradation of sucrose to glucose and fructose. In uninfected plants, this glucose is used as an energy source for basic metabolism. Evolutionary reconstruction of the invertase gene family in fungi has revealed the presence of invertase-encoding genes in all fully sequenced plant pathogens and in only a few mycorrhizal fungi. This highlights a correlation between invertase gene presence and plant pathogen status (37). During infection, glucose is a major nutritional compound of plant pathogens $(31,44,55)$. After Plasmopara viticola inoculation, we followed the expression of NADH-ubiquinone oxidoreductase, laccase, and invertase genes over 7 days postinoculation (dpi) to determinate their optimal time of action. Finally, we performed phylogenetic analyses showing that $P$. viticola genes potentially involved in pathogenesis on grapevine reveal further similarities between oomycetes and true fungi.

\section{MATERIALS AND METHODS}

Biological material. Grapevine plants ( $V$. vinifera L. 'Marselan') obtained as herbaceous cuttings were placed in individual pots $(10$ by 10 by $8 \mathrm{~cm}$ ) containing a mixture of blond peat, sand, and perlite $(4: 1: 1, \mathrm{vol} / \mathrm{vol} / \mathrm{vol})$. The plants were grown in a greenhouse at temperatures of 24 and $18^{\circ} \mathrm{C}$ (day and night, respectively) with a photoperiod of $16 \mathrm{~h}$ of light and at a relative humidity $(\mathrm{RH})$ of $70 \pm 10 \%$. Plants were watered daily and given a liquid fertilizer once a week (53).

Protocols for in vitro culture of the obligate biotroph $P$. viticola have not been established; therefore, a $P$. viticola isolate was maintained on whole plants of Marselan cuttings. At 8 dpi, plants were placed in the dark at $100 \%$ RH overnight. Sporangia were collected from the lower leaf surface using a 1-cm-wide brush immerged in $200 \mathrm{ml}$ of distilled water. For inoculation, the concentration was adjusted to $10^{4}$ sporangia/ml using a Malassez cell, and $3 \mathrm{ml}$ were sprayed on the lower leaf surface of healthy plants (53).

Inoculated leaves were harvested within a 7-day period after inoculation, and were immediately frozen in liquid nitrogen prior to molecular analysis.

Identification of $\boldsymbol{P}$. viticola transcripts. Total RNA was extracted from $100 \mathrm{mg}$ of ground leaves as described by Reid et al. (40) and treated with the DNase 1-Kit (Sigma Aldrich, SaintQuentin-Fallavier, France). The concentration and purity of RNA extracts were determined by spectrophotometry and on $2 \%$ agarose gel. Total RNA $(1 \mu \mathrm{g})$ was used to synthesize the firststrand cDNA using the SuperScript III Reverse Transcriptase Kit (Invitrogen, Saint-Aubin, France) according to the manufacturer's instructions.

First-strand cDNA was used as a template to amplify expressed NADH-ubiquinone oxidoreductase, invertase, and laccase genes of $P$. viticola. Polymerase chain reactions (PCRs) were performed using degenerate primers described in literature for fungal laccase genes (32) or designed from multiple alignments of fungal $\mathrm{NADH}$-ubiquinone oxidoreductase and invertase protein sequences retrieved from GenBank. The primers designed from highly conserved regions used for amplification are listed in Table 1.

For PCR amplification, $100 \mathrm{ng}$ of cDNA was added to the $50-\mu \mathrm{l}$ reaction mixture with final concentrations as follows: $1 \times$ Taq buffer with $\mathrm{MgCl}_{2}$ (New England Biolabs, Evry, France), $160 \mu \mathrm{M}$ each dNTPs, (Promega, Charbonnières, France), $1.2 \mu \mathrm{M}$ each primer, and 1 unit of Taq DNA polymerase (New England Biolabs). PCRs were run on a C1000 thermocycler (Biorad, Marnesla-Coquette, France) with an initial cycle of denaturation (5 min at $94^{\circ} \mathrm{C}$ ) followed by 30 cycles with denaturation $\left(1 \mathrm{~min}\right.$ at $\left.94^{\circ} \mathrm{C}\right)$, annealing $\left(30 \mathrm{~s}\right.$ at $\left.50^{\circ} \mathrm{C}\right)$, and elongation $\left(2 \mathrm{~min}\right.$ at $\left.72^{\circ} \mathrm{C}\right)$, and a final elongation $\left(10 \mathrm{~min}\right.$ at $\left.72^{\circ} \mathrm{C}\right)$. PCR products were directly cloned into a pCR4-TOPO vector, using the TOPO TA Cloning kit (Invitrogen) according to the manufacturer's instructions before sequencing. In total, 20 bacterial clones were selected for each functional gene fragment and the corresponding plasmid inserts were sequenced by AGOWA (LGC Genomics, Berlin) using the M13 rev universal primer. Among the clones checked, 
there was only one sequence for each primer pair. Sequences obtained were compared with sequences available in GenBank with blastx comparisons.

Based on obtained sequences, we designed specific primers to amplify $P$. viticola NADH-ubiquinone oxidoreductase, laccase, and invertase genes. The sequences of these primers are indicated in Table 1. Primers were used on cDNA from sporangia to confirm the absence of contaminants and on cDNA from noninoculated leaves to verify the absence of cross-amplification with plant transcripts. This verification was performed twice in two independent biological replicates. To confirm primer specificities, amplicons were extracted from gels with QIAEX II Gel Extraction Kit (Qiagen, Courtaboeuf, France), cloned, and sequenced as previously described.

Gene expression profiling. Three technical repetitions on two independent biological replicates (i.e., three distinct amplifications per gene using cDNA synthesized from two independent sets of infected-plants) were performed by quantitative PCR on 30 ng of cDNA using Absolute quantitative (q)PCR SYBR green ROX mix on ABI Prism sequence detection system (Applied Biosystem, Villebon-sur-Yvette, France) as follows: initial denaturation $\left(2 \mathrm{~min}\right.$ at $\left.95^{\circ} \mathrm{C}\right), 40$ cycles $\left(30 \mathrm{~s}\right.$ at $95^{\circ} \mathrm{C}, 40 \mathrm{~s}$ at $55^{\circ} \mathrm{C}$, and $45 \mathrm{~s}$ at $\left.72^{\circ} \mathrm{C}\right)$, and final extension $\left(10 \mathrm{~min}\right.$ at $\left.72^{\circ} \mathrm{C}\right)$. A melting curve analysis validated primer gene specificity. Differences in expression during the time-course were calculated according to the " $\Delta \Delta$ method" (38) using actin (46) as reference. To allow comparison between different experiments, a standardized value of 1 was given to the level of expression at 1 dpi. Multiple comparison tests of the data were performed (Student test, oneway analysis of variance, $P<0.05$ ) with SigmaStat version 2.03 software.

Phylogenetic analysis. Expressed $P$. viticola genes, detected by PCR and encoding NADH-ubiquinone oxidoreductase, laccase, and invertase, were deposited at EMBL under the accession numbers FR874042, FR874043, and FR874044, respectively. The deduced protein sequences were aligned and compared with references retrieved from GenBank using the program MUSCLE as implemented in http://www.phylogeny.fr/ (13). All alignments were analyzed using the SeaView version 4 software (25). In order to evaluate the robustness of the maximum-likelihood (ML) analyses, two different substitution models (LG and WAG) were considered $(33,57)$. ML trees were generated with the PhyML 3.0 program (26) and bootstrapping was performed with 1,000 replications. Sequences of Phytophthora capsici, P. infestans, $P$. ramorum, $P$. sojae, and $H$. arabidopsidis were specifically obtained and used for phylogenies. Bootstrap values of $<50$ are not presented on trees. Specific blasts were performed on brown algae and diatoms. If no sequence or sequences with a too low percentage of identity to correspond to the correct proteins were found, these organisms were excluded from the analysis.

\section{RESULTS}

Identification of Plasmopara viticola sequences and gene expression analysis. The designed degenerate primers Nuo-D1 and Nuo-D2 produced a PCR product of $344 \mathrm{bp}$ using the cDNA synthesized from Plasmopara viticola-infected leaves as a template. This $P$. viticola sequence showed the highest identity (Evalue: 6e-74) to a Phytophthora infestans NADH-ubiquinone oxidoreductase and was named PvNuo (Table 1). With the specific primer pair Nuo-S1 and Nuo-S2, we obtained a PCR product with sporangial cDNA. Using a noninoculated grapevine leaf (Fig. 1) as control, we confirmed that the PvNuo belongs to Plasmopara viticola and not to a potential contamination. We followed the PvNuo expression during 7 dpi (Fig. 2A). A basal level of expression occurred at $1 \mathrm{dpi}$ and from $3 \mathrm{dpi}$ until the end of the investigation; whereas, at $2 \mathrm{dpi}$, the $P v N u o$ gene was significantly upregulated with a ninefold induction.

With the degenerate primers $\mathrm{Cu} 1 \mathrm{AF}$ and $\mathrm{Cu} 2 \mathrm{R}$, developed for ascomycete laccases (32), we obtained a 148-bp-long PCR product of the expected size. $P$. viticola sequence presented the highest identity to a Phytophthora infestans sequence (E-value: 1e-23) coding for a multicopper oxidase also known as laccase (Table 1).

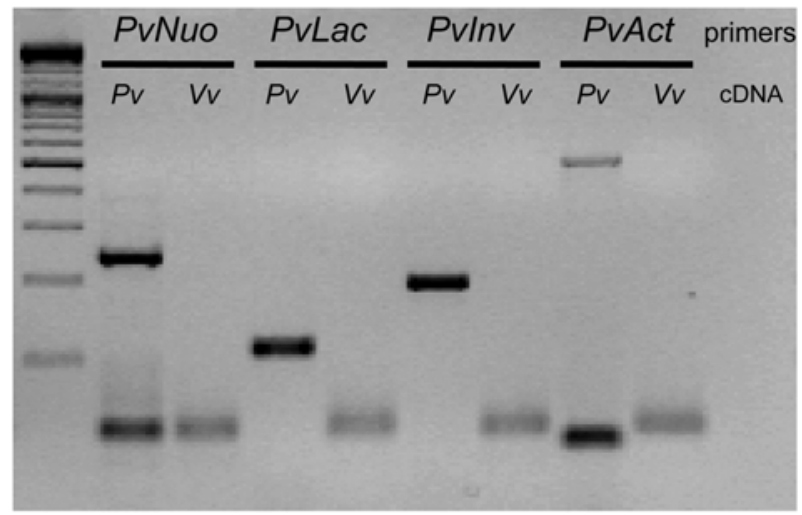

Fig. 1. Agarose gel illustrating the specificity of the specifically designed primers for NADH-ubiquinone oxidoreductase (PvNuo), laccase (PvLac), invertase $(P v I n v)$, and actin $(P v A c t)$. Primers were used on cDNA from Plasmopara viticola sporangia $(P v)$ or from uninfected grapevine plant $(V v)$. Polymerase chain reaction was performed twice on two independent biological experiments. A 100-bp DNA molecular marker confirmed amplification at the expected size.

TABLE 1. Degenerate and specific primers used to specifically amplify expressed Plasmopara viticola genes encoding NADH-ubiquinone oxidoreductase $(P v N u o)$, laccase $(P v L a c)$, and invertase $(P v I n v)$ enzymes in infected leaves ${ }^{\mathrm{a}}$

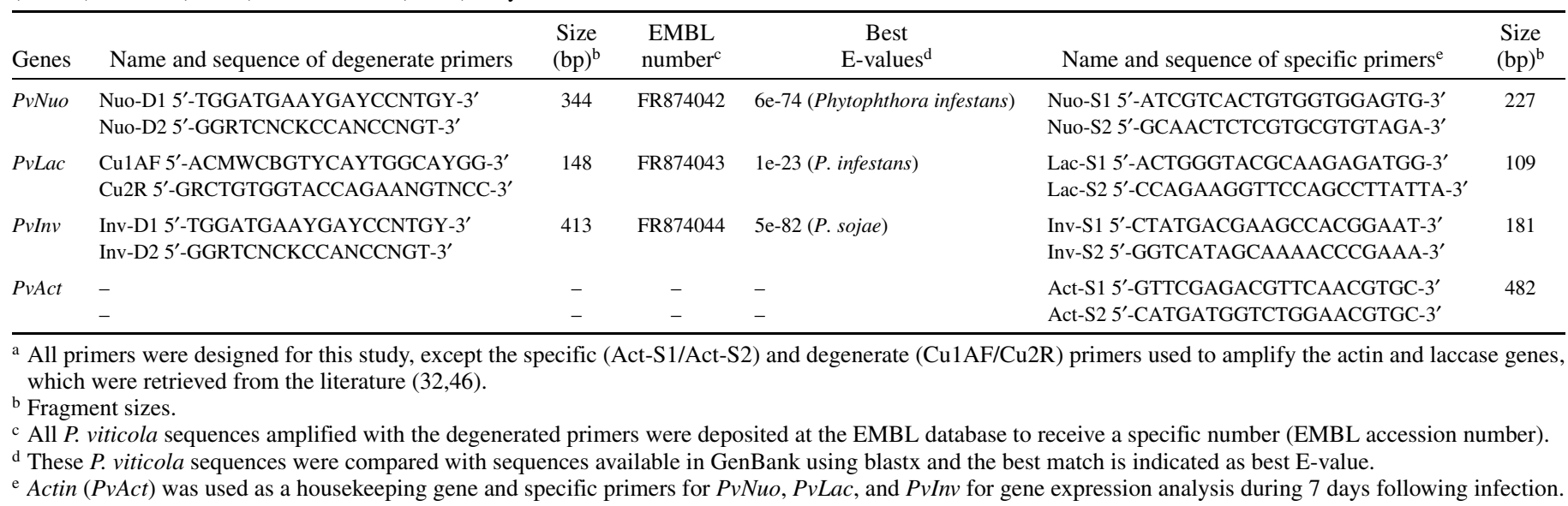


The specific primers Lac-S1 and Lac-S2 were designed to confirm the lack of contamination (Fig. 1) and to follow the expression of the Plasmopara viticola laccase-coding gene named PvLac. PvLac was significantly overexpressed at 2 to $5 \mathrm{dpi}$ (Fig. 2B) compared with $1 \mathrm{dpi}$. At $5 \mathrm{dpi}$, there was a 3.4-fold increase in laccase gene expression compared with $1 \mathrm{dpi}$, before returning to the initial expression level at 6 and $7 \mathrm{dpi}$.

Based on fungal databases, we designed two degenerate primers, Inv-D1 and Inv-D2. We successfully amplified a 413-bp PCR product that presented the highest identity to a Phytophthora sojae invertase encoding gene (E-value: 5e-82) (Table 1). Inv-S1and Inv-S2-specific primers were designed for quantitative gene expression analysis. Using these primers, we obtained a PCR product with sporangial cDNA and no amplification in a noninoculated grapevine leaf; thus, we confirmed its specificity to Plasmopara viticola (Fig. 1). There was no difference between the transcripts encoding the $P$. viticola invertase $(P v \operatorname{Inv})$ after 1 and 2 dpi (Fig. 2C). Subsequently, the transcript level started a significant increase from $3 \mathrm{dpi}$, reaching a plateau (4 to $6 \mathrm{dpi}$ ), before a slight decrease at $7 \mathrm{dpi}$.
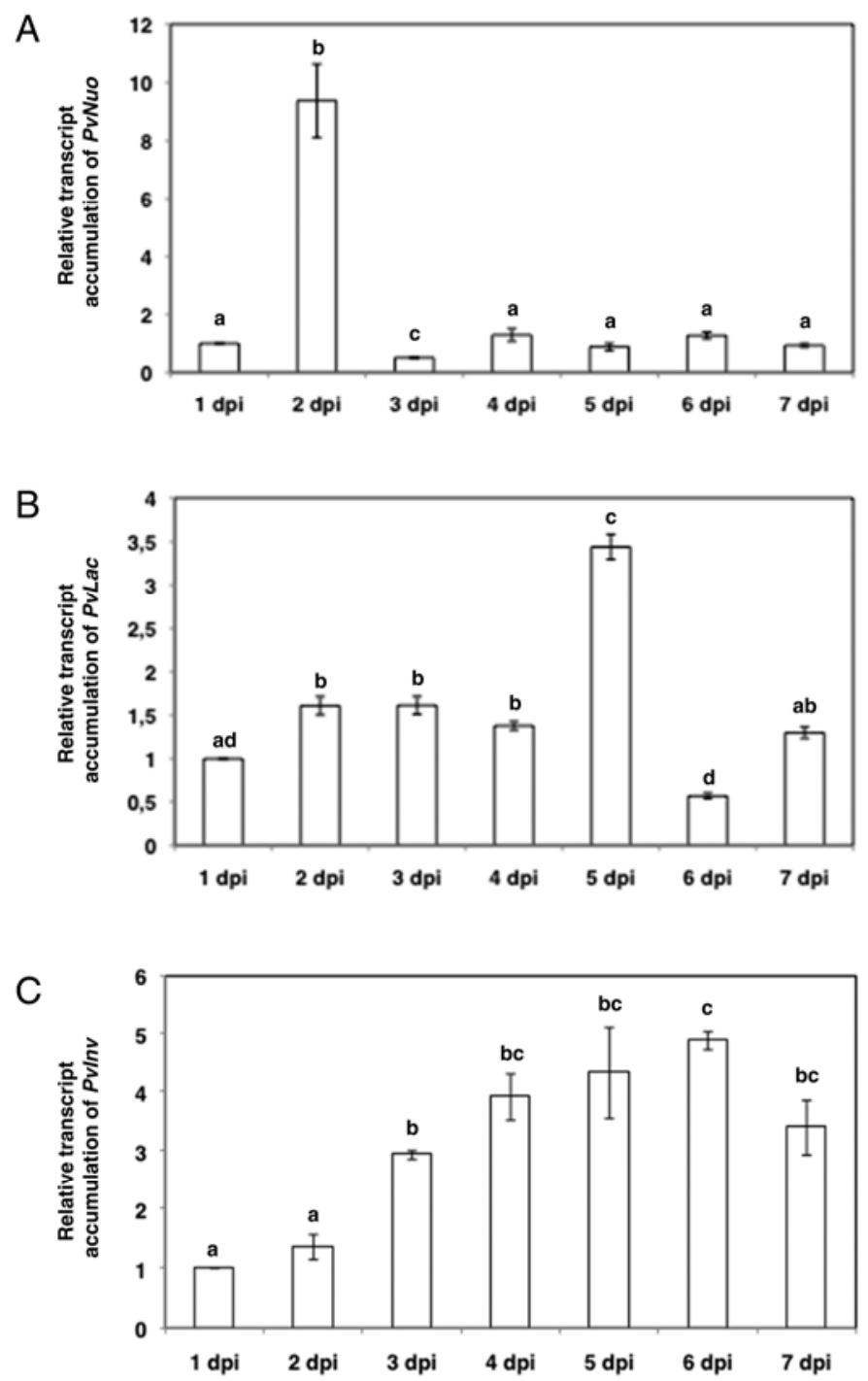

Fig. 2. Expression of Plasmopara viticola genes during 7 days postinoculation (dpi). The transcript accumulation of genes encoding A, NADH-ubiquinone oxidoreductase $P v N u o ; \mathbf{B}$, laccase $P v L a c$; and $\mathbf{C}$, invertase $P v I n v$ was analyzed by real-time quantitative polymerase chain reaction. After normalization with actin, results are represented as mean relative abundance \pm standard error of three technical replicates from two biological experiments $(n=6)$ for each day postinoculation. Values with different letters (a, b, c, or d) are significantly different (Student test, one-way analysis of variance test, $P<0.05$ ).
Phylogenetic analysis of $\boldsymbol{P}$. viticola-deduced proteins. The ML phylogenetic tree based on comparative analysis of the deduced $P$. viticola NADH-ubiquinone oxidoreductase and the most similar protein sequences retrieved from GenBank distinguished two main groups with high bootstrap support values: one group only composed of Straminipila organisms (oomycetes, brown algae, and diatoms) and a second group gathering Archaeplastida organisms (green algae and land plants) and fungi (basidiomycetes and ascomycetes) (Fig. 3). In the Straminipila clade, $P$. viticola NADH-ubiquinone oxidoreductase clustered with sequences from the other oomycetes Phytophthora capsici, $P$. infestans, $P$. ramorum, $P$. sojae, $H$. arabidopsidis, and Albugo laibachii. Despite moderate support values, Archaeplastida organisms (composed of green algae and land plants), basidiomycetes, and ascomycetes tend to form three separate clades.

Concerning the phylogeny of multicopper oxidases, land plant laccases formed a distinct, separate cluster from an oomycetesfungi-algae group. Within this group, the Plasmopara viticola sequence was most homologous with proteins from Phytophthora capsici, $P$. infestans, $P$. ramorum, $P$. sojae, and $H$. arabidopsidis, but no sequence matched $A$. laibachii (Fig. 4).

There were several sequences coding for proteins that were closely related to Plasmopara viticola invertase in land plants and ascomycetes but only two basidiomycete sequences. $P$. viticola invertase was largely homologous with invertases from other oomycetes. This cluster was closely related to ascomycete sequences (Fig. 5). The ascomycete sequences formed two clades, one associated to the oomycete sequences and one more-closely related to the basidiomycete sequences found for Ustilago maydis and Sporisorium reilianum. Fungal and oomycete invertases, which grouped together, were clearly separated from those of land plants. Only one brown algae (Aureococcus anophagefferens) sequence was found with enough amino acid homology. A. anophagefferens clustered with land plants. The separation of microbial invertases and plant or algae invertases was reinforced by a high bootstrap support value.

\section{DISCUSSION}

Differential expression of $P$. viticola genes during the infection process. The $P$. viticola gene encoding NADH-ubiquinone oxidoreductase was expressed throughout leaf infection, with no difference between 1 and after 3 dpi whereas, at 2 dpi, the NADHubiquinone oxidoreductase gene was overexpressed (Fig. 2A). At the time of infection, $P$. viticola used encysted zoospore reserves to develop its first hyphal and haustorial structures (16). NADHubiquinone oxidoreductase is involved in the generation of the proton motive force. Because the proton motive force can be used for synthesis of ATP and active transport of various nutrients (1), this step in the infection strategy is an energetically critical point. At this stage, $P$. viticola has just started to develop nutritional structures, which will allow nutrient uptake from the plant. At the same time that $P$. viticola is penetrating deeper into the leaf, it is in contact with a broad spectrum of grapevine molecules, including defense compounds which could act on $P v N u o$ regulation. In fungi, NADH-ubiquinone oxidoreductases are the target of antimicrobial compounds regulating their expression and are involved in resistance to the plant's biochemical defenses $(15,49)$. Because this gene was expressed early in P. viticola and for a very short time, it is tempting to speculate that NADH-ubiquinone oxidoreductase could be involved in the capacity of plantassociated microbes to interact with their host. Such a hypothesis is supported by evidence of impaired root-colonization ability (8) and reduced virulence (48) of Pseudomonas fluorescens and $F$. graminearum mutants, respectively, with altered $\mathrm{NADH}-$ ubiquinone oxidoreductases.

The Plasmopara viticola laccase gene was expressed throughout infection (Fig. 2B) but upregulation was only apparent at 


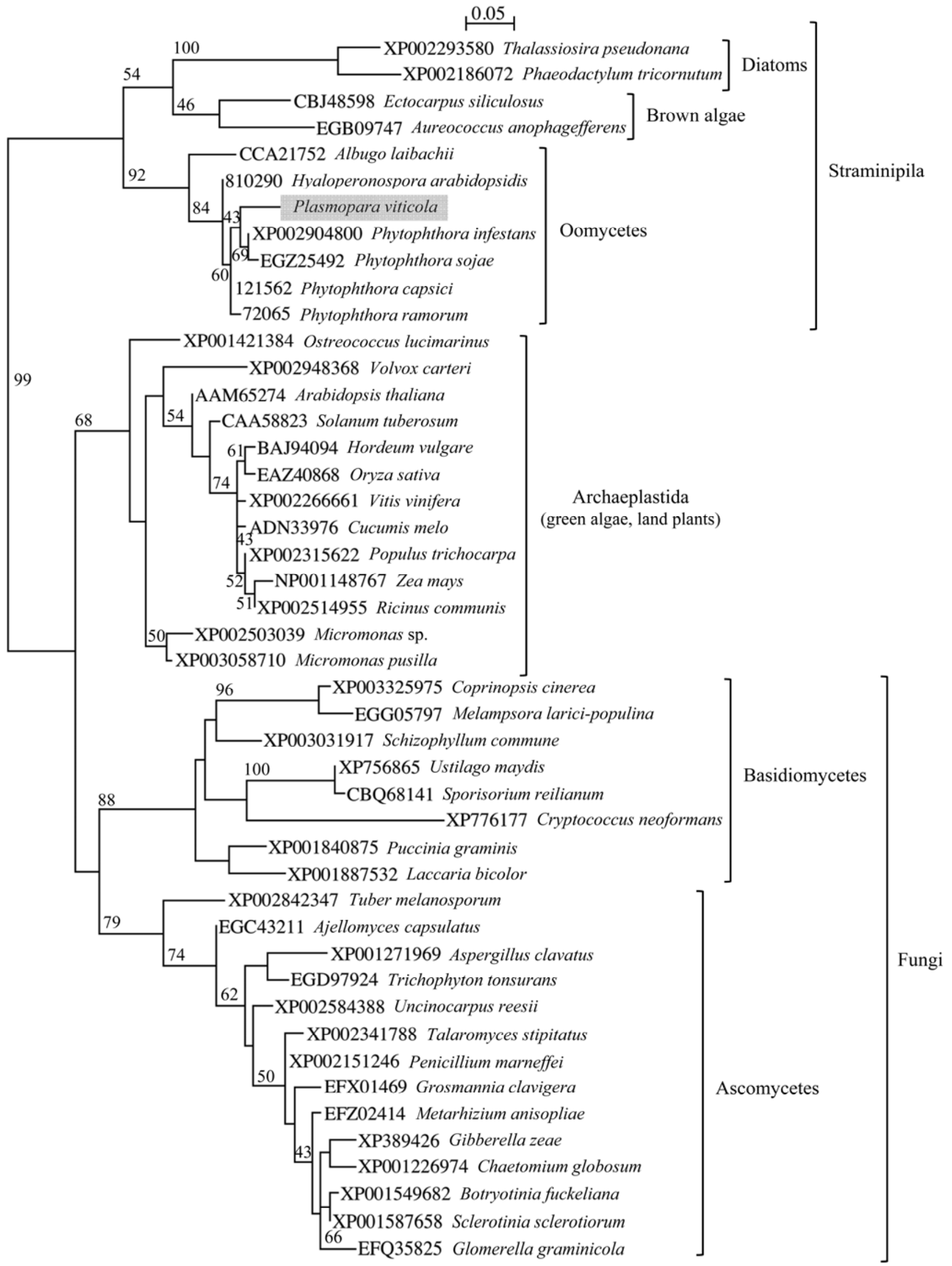

Fig. 3. Maximum-likelihood (ML) phylogenetic tree based on the comparative analysis of the deduced Plasmopara viticola NADH-ubiquinone oxidoreductase and the closest protein sequences retrieved from GenBank. The robustness of the tree topology was tested by bootstrap analysis with 1,000 resamplings, using LG and WAG (substitution models from Le and Gascuel [33] or Whelan and Goldman [57]) models. The ML phylogenetic tree obtained with the LG model is represented. 
$5 \mathrm{dpi}$, before a large decrease in expression at 6 dpi. Otherwise, no differences in laccase mRNA content were detected between the first 4 days of infection and the last day ( 7 dpi). The occurrence of laccases in phytopathogenic ascomycetes has previously been well documented. Iyer and Chatto (30) described the purification and characterization of a laccase in Magnaporthe grisea, without relating it to infection. Dutch elm disease has been associated with laccase secretion in Ophiostoma ulmi (6) and laccase gene expression was detected in Cryphonectria parasitica after in vitro induction (10). Botrytis cinerea on

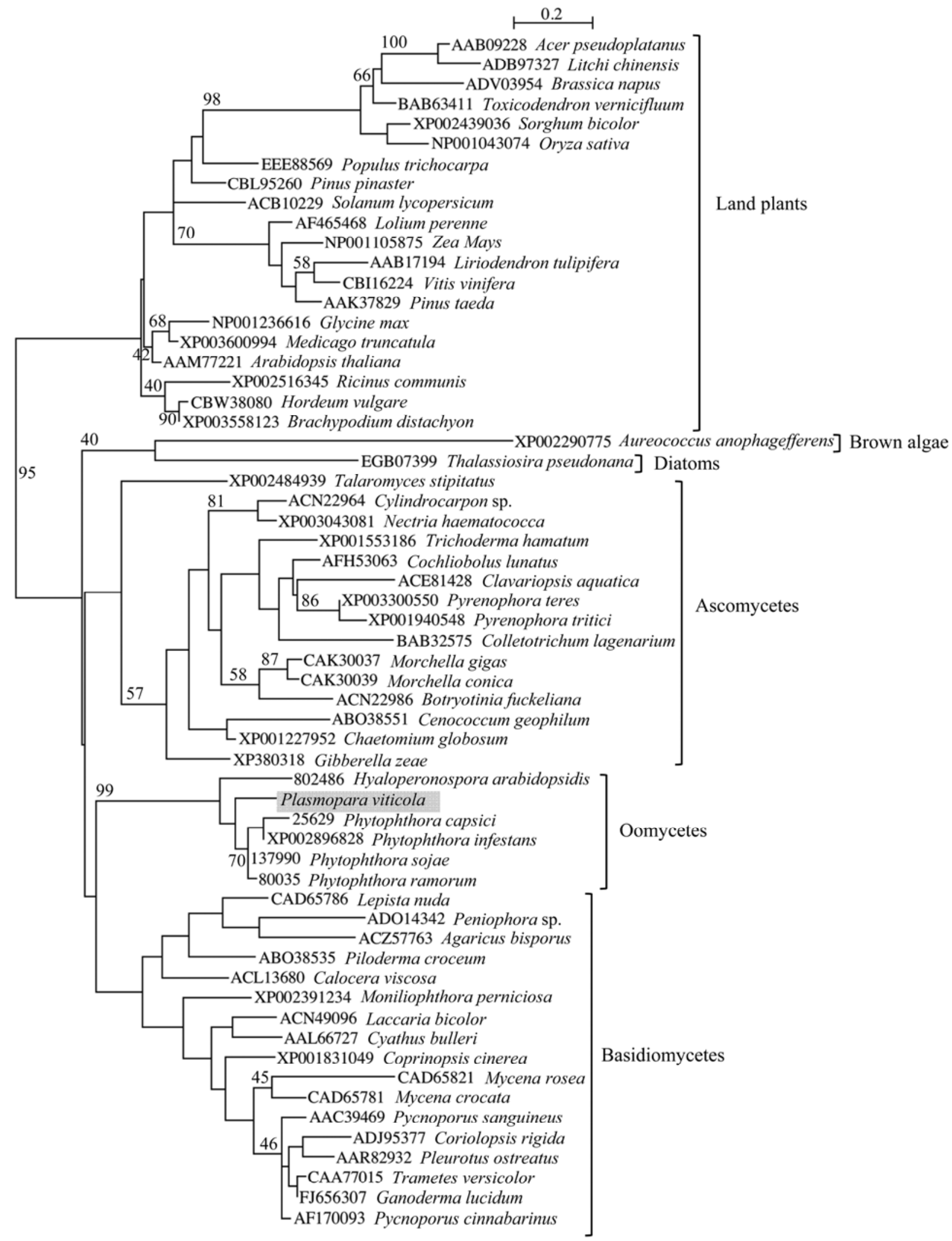

Fig. 4. Maximum-likelihood (ML) phylogenetic tree based on the comparative analysis of the deduced Plasmopara viticola laccase and the closest protein sequences retrieved from GenBank. The robustness of the tree topology was tested by bootstrap analysis with 1,000 resamplings, using LG and WAG (substitution models from Le and Gascuel [33] or Whelan and Goldman [57]) models. The ML phylogenetic tree obtained with the LG model is represented. 
grapevine neutralizes the toxicity of the stilbenic phytoalexin trans-resveratrol through laccase secretion and activity (19). During infection with $P$. viticola, grapevine expresses stilbene synthase genes (42). Recently, using the same biological material, Gamm et al. (21) described the significant overexpression of three grapevine genes involved in phytoalexin biosynthesis after 5 dpi.
Thus, it is tempting to suppose that the production of these chemical weapons by plants is counterbalanced by the upregulation of detoxifying enzymes such as the laccase which is synthesized synchronously in $P$. viticola.

The invertase-coding gene from $P$. viticola was differentially expressed at the time of infection. Transcript levels increased

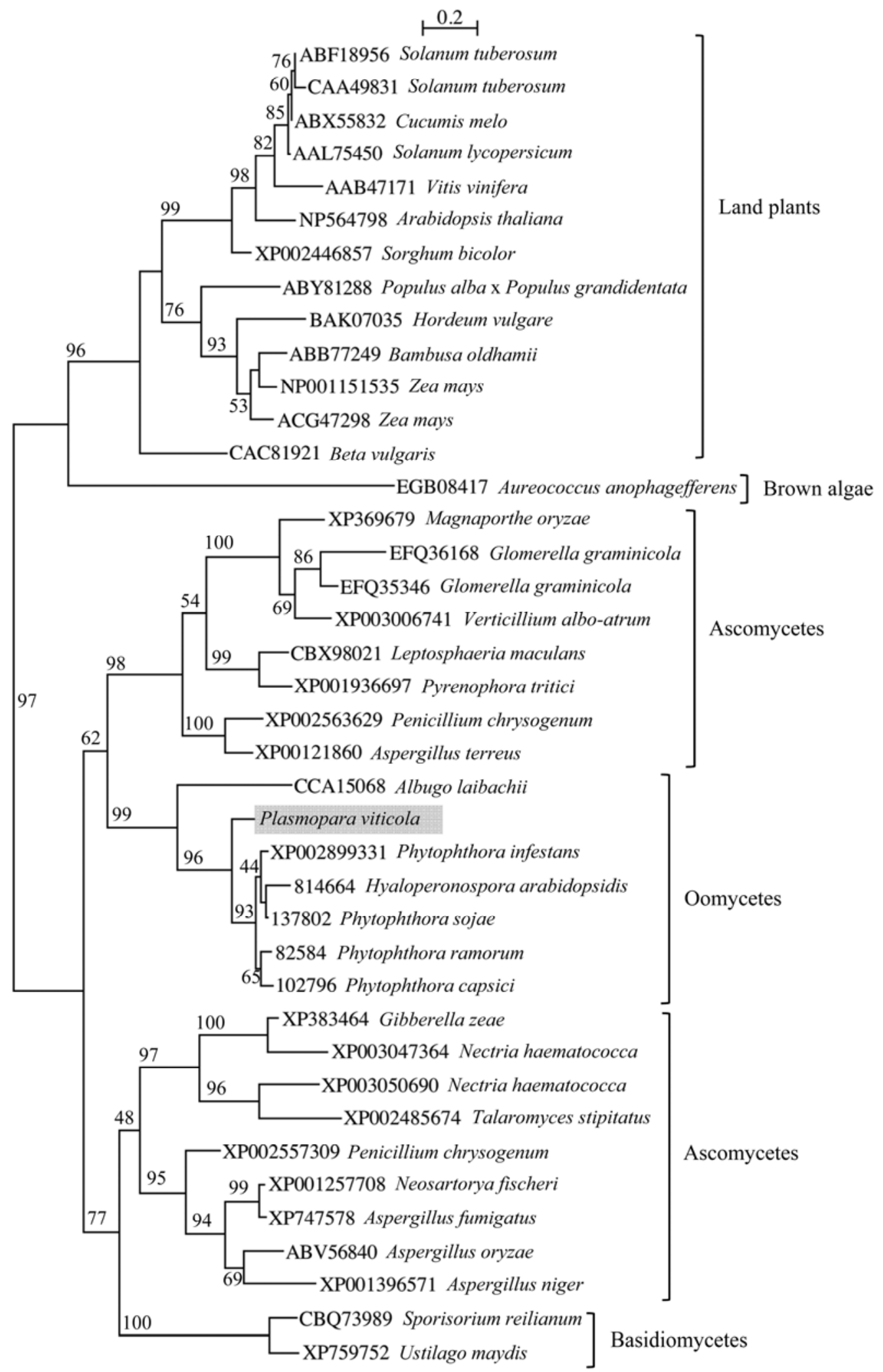

Fig. 5. Maximum-likelihood (ML) phylogenetic tree based on the comparative analysis of the deduced Plasmopara viticola invertase and the closest protein sequences retrieved from GenBank. The robustness of the tree topology was tested by bootstrap analysis with 1,000 resamplings, using LG and WAG (substitution models from Le and Gascuel [33] or Whelan and Goldman [57]) models. The ML phylogenetic tree obtained with the LG model is represented. 
between 1 and 4 dpi, before reaching a plateau until the end of the study (Fig. 2C). P. viticola may increase the production of this invertase until the establishment of a finely tuned balance between the production of sucrose in leaf and its uptake. The relatively high and unmodified expression of the $P$. viticola invertase gene during the last 4 days of the investigation may be related to the obligate status of the pathogen, which has to maintain a balance between its requirements and the necessity to keep the plant tissue alive for as long as possible. Several studies have described the role of pathogen invertases during plant infection by necrotrophic fungi (e.g., B. cinerea [44] and Sclerotinia sclerotiorum [31]) or biotrophic fungi (e.g., Uromyces fabae [55]). However, to our knowledge, oomycete invertase expression during infection has not been described until now. Recently, Gamm et al. (20) described an increase in invertase activity during the progressive infection of grapevine leaves by $P$. viticola. It was not possible to attribute this increase to the control of plant invertase by the pathogen or to the possible action of a microbial invertase. Once established within the plant tissue, we can imagine that $P$. viticola could act as a sink for carbohydrates. Complementing plant invertases, $P$. viticola possesses (as do other oomycetes) an enzymatic tool that allows it to produce more glucose for its own growth and, thus, alter the carbohydrate ratios. Together with extracellular polysaccharide depolymerizing enzymes (41), oomycete invertases might allow efficient sugar acquisition and lead to pathogen proliferation in plant tissue.

Depending on the gene studied, $P$. viticola is most closely related to either Straminipila or Opisthokonta. Based on fungal protein databases, we designed degenerated primers to identify three unknown $P$. viticola genes. Using specific primers and a qPCR approach, we showed that these genes are differentially expressed during grapevine leaf infection. The direct amplification of unknown sequences can only be performed with degenerate primers. Such primers are designed from conserved protein regions detected after the alignment of available sequences retrieved from GenBank. Because of the presence of introns in eukaryotic genomes, such primers don't always work on DNA. For this reason, we had to deal with cDNA and we used amino acid sequences as the basis for our investigation. We performed phylogenetic analysis with the deduced protein of nucleotide sequences obtained after amplification of cDNA. Phylogenetic analyses showed that $P$. viticola genes could be differentially related to Straminipila or to Opisthokonta sequences, depending on their function. Thus, NADH-ubiquinone oxidoreductase-encoding sequences were consistent with the consensus phylogeny of eukaryotes because $P$. viticola, along with other oomycetes, was associated with diatoms and brown algae (3). Again, with respect to the consensus phylogeny based on a comparison of the small-subunit ribosomal RNA, fungal and land plant NADH-ubiquinone oxidoreductases were separated into two groups, related to Opisthokonta and Archaeplastida, respectively. It is not surprising that $P$. viticola was most-closely related to other Straminipila using the mitochondrial NADHubiquinone oxidoreductase gene because phylogenetic classifications of organisms based on ribosomal RNA or mitochondrial sequences give similar results $(18,47)$.

Starting with the hypothesis that phytopathogenic fungi and oomycetes use similar strategies to invade plants, and that there is an extensive pattern of HGT between these kingdoms (41), we investigated $P$. viticola genes encoding secreted enzymes previously described in fungi and involved in the degradation of polymers in the external environment. We successfully amplified $P$. viticola genes encoding a laccase and an invertase with degenerate primers designed with fungal databases. To confirm that $P$. viticola genes and those of other organisms were similar, we constructed phylogenetic trees based on the comparative analysis of laccase and invertase protein sequences from oomycetes, fungi, and land plants. Götesson et al. (24) and Wu et al. (59) described cell-wall-degrading enzymes from oomycetes with close homologies with fungal polygalacturonases in Phytophthora cinnamomi and $P$. parasitica, respectively. Richard et al. (41) enlarged this observation to other extracellular enzymes such as endoglucanases and endoxylanases in several oomycete species. Similarly, the Plasmopara viticola laccase-gene, as well as its homologues in other oomycete species, tends to show close homologies with fungal laccases. However, an alternative topology grouping oomycetes together with brown algae and diatoms cannot be refuted due to the lack of available Straminipila sequences in public databases and to the lack of support for the lineages in the phylogenetic tree. The absence of laccase gene in the Albugo laibachii genome could be explained by a functional difference in the infection process between downy mildews and white blister rusts, because obligate biotrophy seems to be an ancient occurrence in white blister rusts, whereas downy mildews more likely evolved from hemibiotrophs (51). Moreover, A. laibachii forms a deeper branch sister to the Phytophthora/Hyaloperonospora clade and possesses a distinct repertoire of secreted proteins compared with other oomycete plant pathogens (41). Among the fungi present, it was not possible to highlight plant-associated fungi more than plant-nonassociated fungi, because saprophytic (e.g., Pycnoporus cinnabarinus and Trametes versicolor), symbiotic (e.g., Laccaria bicolor and Piloderma croceum), and phytopathogenic (e.g., Botryotinia fuckeliana and Gibberella zeae) fungi were all found in various proportions. This arrangement could simply be due to the large spectrum of roles for laccases, because such multi-copper oxidases contribute to several developmental and metabolic processes, including lignin and polyphenols degradation and morphogenesis of multihyphal structures (e.g., fruiting body and rhizomorph formation) (4). Compared with laccases, the phylogenetic analysis of invertases showed a net separation, supported by a high bootstrap value, between oomycete and other Straminipila sequences. Indeed, only one brown algae (Aureococcus anophagefferens) invertase sequence was found in all available databases and it clearly clusters with land plants. However, this statement should be cautiously taken into account because the number of fully sequenced Straminipila is limited. In this case, there were enough similarities between fungi and oomycetes to form a mixed group composed of Opisthokonta and Straminipila. More interestingly, most of the related invertase sequences belonged to phytopathogenic fungi (e.g., Glomerella graminicola, Gibberella zeae, Nectria haematococca, and Ustilago maydis). This observation seems consistent with the large repertoire of oomycete enzymes and transporters involved in sugar acquisition and derived from fungi by HGT (41). Moreover, our results stay in agreement with the work of Werner et al. (56), who reported that Plasmopara viticola chitin synthase genes were closely related to similar genes in true fungi and involved in plant infection processes.

Fungi and oomycetes use infection strategies that have much in common. Their specialized infection structures such as appressoria, infection hyphae, and haustoria share many features. In this work, we show that, depending on the gene studied, phylogenetic proximity may shed some light on the common strategies used by fungi and oomycetes for successful host colonization. HGT or convergent evolution could explain these results. Interspecific hybridization in plant-associated fungi and oomycetes also contributes to adaptation to new niches such as new host species, and increased or decreased virulence (45). For example, Newcombe et al. (36) described a new species of rust fungus, Melampsora $\times$ columbiana, which is a natural hybrid between Melampsora medusae and M. occidentalis able to colonize different plant hosts with variable levels of virulence. Similarly, several hybrid Phytophthora spp. have been generated in the laboratory and often exhibit broadened host ranges due to the acquisition of new genes (45). Recently, Haegeman et al. (28) described a fascinating mechanism: based on recent genomic studies on plant-associated 
nematodes, they reviewed the HGT from plant-associated fungi and bacteria to nematodes. Genes coding for invertases have been found in root-knot nematodes (28). Invertases, which are generally absent in animals, could increase the glucose concentration that is available to nematodes. If similar mechanisms exist between phytopathogenic fungi and oomycetes, as demonstrated by Richards et al. (41) for several Phytophthora spp. using wholegenome and gene-by-gene phylogenetic analysis, HGT could facilitate the presence of close-to-fungi genes in $P$. viticola. To prove the involvement of these close-to-fungi genes in $P$. viticola infection process and in mechanisms similar to phytopathogenic fungi, additional functional analyses are needed. Sequencespecific RNA silencing is an invaluable tool that allows the functional analysis and screening of genes in order to identify potential pathogenicity factors. Such an approach could then be used in future experiments to characterize in more detail the role of the $P$. viticola genes identified in this study during the plant infection process.

\section{ACKNOWLEDGMENTS}

A. Gauthier was supported by a grant from the European social fund, the Conseil Régional de Bourgogne, and the BIVB. This work was financially supported by the ANR Génoplante Safegrape project (08GENO-148G). We thank M. Adrian, M.-C. Héloir, and C. Dubreuil for helpful discussions; and T. M. Robson (Division of Plant Biology, University of Helsinki), for kindly improving the language of the manuscript. EMBL accession numbers: FR874042, FR874043, and FR874044.

\section{LITERATURE CITED}

1. Anraku,Y., and Gennis, R. 1987. The aerobic respiratory chain of Escherichia coli. TIBS 12:262-266.

2. Aziz, A., Poinssot, B., Daire, X., Adrian, M., Bezier, A., Lambert, B., Joubert, J. M., and Pugin, A. 2003. Laminarin elicits defense responses in grapevine and induces protection against Botrytis cinerea and Plasmopara viticola. Mol. Plant-Microbe Interact. 16:1118-1283.

3. Baldauf, S. L. 2008. An overview of the phylogeny and diversity of eukaryotes. J. Syst. Evol. 46:263-273.

4. Baldrian, P. 2006. Fungal laccases-occurrence and properties. FEMS Microbiol. Rev. 30:215-242.

5. Baxter, L., Tripathy, S., Ishaque, N., Boot, N., Cabral, A., Kemen, E., Thines, M., Ah-Fong, A., Anderson, R., Badejoko, W., Bittner-Eddy, P., Boore, J. L., Chibucos, M. C., Coates, M., Dehal, P., Delehaunty, K., Dong, S., Downton, P., Dumas, B., Fabro, G., Fronick, C., Fuerstenberg, S. I., Fulton, L., Gaulin, E., Govers, F., Hughes, L., Humphray, S., Jiang, R. H., Judelson, H., Kamoun, S., Kyung, K., Meijer, H., Minx, P., Morris, P., Nelson, J., Phuntumart, V., Qutob, D., Rehmany, A., Rougon-Cardoso, A., Ryden, P., Torto-Alalibo, T., Studholme, D., Wang, Y., Win, J., Wood, J., Clifton, S. W., Rogers, J., Van den Ackerveken, G., Jones, J. D., McDowell, J. M., Beynon, J., and Tyler, B. M. 2010. Signatures of adaptation to obligate biotrophy in the Hyaloperonospora arabidopsidis genome. Science 330:1549-1551.

6. Binz, T., and Canevascini, G. 1996. Differential production of laccases in Dutch elm disease pathogens Ophiostoma ulmi and $O$. novo ulmi. Mycol. Res. 100:1060-1064.

7. Blum, M., Waldner, M., and Gisi, U. 2010. A single point mutation in the novel PvCesA3 gene confers resistance to the carboxylic acid amide fungicide mandipropamid in Plasmopara viticola. Fungal Genet. Biol. 47:499-510.

8. Camacho Carvajal, M. M., Wijfjes, A. H. M., Mulders, I. H. M., Lugtenberg, B. J. J, and Bloemberg, G. V. 2002. Characterization of NADH dehydrogenases of Pseudomonas fluorescens WCS365 and their role in competitive root colonization. Mol. Plant-Microbe Interact. 15:662-671.

9. Carzaniga, R., Bowyer, P., and O'Connell, R. J. 2001. Production of extracellular matrices during development of infection structures by the downy mildew Peronospora parasitica. New Phytol. 149:83-93.

10. Choi, G. H., Larson, T. G., and Nuss, D. L. 1992. Molecular analysis of the laccase gene from the chestnut blight fungus and selective suppression of its expression in an isogenic hypovirulent strain. Mol. Plant-Microbe Interact. 5:119-128.

11. Chung, H. J., Kwon, B. R., Kim, J. M., Park, S. M., Park, J. K., Cha, B. J., Yang, M. S., and Kim, D. H. 2008. A tannic acid-inducible and hypoviralregulated laccase 3 contributes to the virulence of the chestnut blight fungus Cryphonectria parasitica. Mol. Plant-Microbe Interact. 21:15831590.

12. Dekkers, L. C., van der Bij, A. J., Mulders, I. H. M., Phoelich, C. C., Wentwoord, R. A., Glandorf, D. C., Wijffelman, C. A., and Lugtenberg, B. J. J. 1998. Role of the O-antigen of lipopolysaccharide, and possible roles of growth rate and of NADH-ubiquinone oxidoreductase (nuo) in competitive tomato root-tip colonization by Pseudomonas fluorescens WCS365. Mol. Plant-Microbe Interact. 11:763-771.

13. Dereeper, A., Guignon, V., Blanc, G., Audic, S., Buffet, S., Chevenet, F., Dufayard, J. F., Guindon, S., Lefort, V., Lescot, M., Claverie, J. M., and Gascuel, O. 2008. Phylogeny.fr: Robust phylogenetic analysis for the non-specialist. Nucleic Acids Res. 36:465-469.

14. Díez-Navajas, A. M., Wiedemann-Merdinoglu, S., Greif, C., and Merdinoglu, D. 2008. Nonhost versus host resistance to the grapevine downy mildew, Plasmopara viticola, studied at the tissue level. Phytopathology 98:776-780.

15. Dinamarco, T. M., Pimentel, B. C. F., Savoldi, M., Malavazi, I., Soriani, F. M., Uyemura, S.A., Ludovico, P., Goldman, M. H. S., and Goldman, G. H. 2010. The roles played by Aspergillus nidulans apoptosis-inducing factor (AIF)-like mitochondrial oxidoreductase (AifA) and NADHubiquinone oxidoreductases (NdeA-B and NdiA) in farnesol resistance. Fungal Genet. Biol. 47:1055-1069.

16. Dubreuil-Maurizi, C., Trouvelot, S., Frettinger, P., Pugin, A., Wendehenne, D., and Poinssot, B. 2010. $\beta$-Aminobutyric acid primes an NADPH oxidase-dependent reactive oxygen species production during grapevinetriggered immunity. Mol. Plant-Microbe Interact. 23:1012-1021.

17. Duplessis, S., Cuomo, C. A., Lin, Y. C., Aerts, A., Tisserant, E., VeneaultFourrey, C., Joly, D. L., Hacquard, S., Amselem, J., Cantarel, B. L., Chiu, R., Coutinho, P. M., Feau, N., Field, M., Frey, P., Gelhaye, E., Goldberg, J., Grabherr, M. G., Kodira, C. D., Kohler, A., Kües, U., Lindquist, E. A., Lucas, S. M., Mago, R., Mauceli, E., Morin, E., Murat, C., Pangilinan, J. L., Park, R., Pearson, M., Quesneville, H., Rouhier, N., Sakthikumar, S., Salamov, A. A., Schmutz, J., Selles, B., Shapiro, H., Tanguay, P., Tuskan, G. A., Henrissat, B., Van de Peer, Y., Rouzé, P., Ellis, J. G., Dodds, P. N., Schein, J. E., Zhong, S., Hamelin, R. C., Grigoriev, I. V., Szabo, L. J., and Martin, F. 2011. Obligate biotrophy features unraveled by the genomic analysis of rust fungi. Proc. Natl. Acad. Sci. USA 108:9166-9171.

18. Emelyanov, V. V. 2001. Rickettsiaceae, rickettsia-like endosymbionts, and the origin of mitochondria. Biosci. Rep. 21:1-17.

19. Favaron, F., Lucchetta, M., Odorizzi, S., da Cunha, A. T. P., and Sella, L. 2009. The role of grape polyphenols on trans-resveratrol activity against Botrytis cinerea and of fungal laccase on the solubility of putative grape PR proteins. J. Plant Pathol. 91:579-588.

20. Gamm, M., Héloir, M. C., Bligny, R., Vaillant-Gaveau, N., Trouvelot, S., Alcaraz, G., Frettinger, P., Clément, C., Pugin, A., Wendehenne, D., and Adrian, M. 2011. Changes in carbohydrate metabolism in Plasmopara viticola infected grapevine leaves. Mol. Plant-Microbe Interact. 24:10611073.

21. Gamm, M., Héloir, M. C., Kelloniemi, J., Poinssot, B., Wendehenne, D., Adrian, M. 2011. Identification of reference genes suitable for qRT-PCR in grapevine and application for the study of the expression of genes involved in pterostilbene synthesis. Mol. Genet. Genomics. 285:273-285.

22. Geiger, J. P., Nicole, M., Nandris, D., and Rio, B. 1986. Root rot disease of Hevea brasiliensis. I: Physiological and biochemical aspects of aggression. Eur. J. Pathol. 16:22-37.

23. Glazebrook, J. 2005. Contrasting mechanisms of defense against biotrophic and necrotrophic pathogens. Annu. Rev. Phytopathol. 43:205227.

24. Götesson, A., Marshall, J. S., Jones, D. A., and Hardham, A. R. 2002. Characterization and evolutionary analysis of a large polygalacturonase gene family in the oomycete plant pathogen Phytophthora cinnamomi. Mol. Plant-Microbe Interact. 15:907-921.

25. Gouy, M., Guindon, S., and Gascuel, O. 2010. SeaView version 4: A multiplatform graphical user interface for sequence alignment and phylogenetic tree building. Mol. Biol. Evol. 27:221-224.

26. Guindon, S., Dufayard, J. F., Lefort, V., Anisimova, M., Hordijk, W., and Gascuel, O. 2010. New algorithms and methods to estimate maximumlikelihood phylogenies: Assessing the performance of PhyML 3.0. Syst. Biol. 59:307-321.

27. Haas, B. J., Kamoun, S., Zody, M. C., Jiang, R. H., Handsaker, R. E., Cano, L. M., Grabherr, M., Kodira, C. D., Raffaele, S., Torto-Alalibo, T., Bozkurt, T. O., Ah-Fong, A. M., Alvarado, L., Anderson, V. L., Armstrong, M. R., Avrova, A., Baxter, L., Beynon, J., Boevink, P. C., Bollmann, S. R., Bos, J. I., Bulone, V., Cai, G., Cakir, C., Carrington, J. C., Chawner, M., Conti, L., Costanzo, S., Ewan, R., Fahlgren, N., Fischbach, M. A., Fugelstad, J., Gilroy, E. M., Gnerre, S., Green, P. J., Grenville-Briggs, L. J., Griffith, J., Grünwald, N. J., Horn, K., Horner, N. R., Hu, C. H., Huitema, E., Jeong, D. H., Jones, A. M., Jones, J. D., Jones, R. W., Karlsson, E. K., Kunjeti, S. G., Lamour, K., Liu, Z., Ma, L., Maclean, D., Chibucos, M. C., McDonald, H., McWalters, J., Meijer, H. 
J., Morgan, W., Morris, P. F., Munro, C. A., O’Neill, K., Ospina-Giraldo, M., Pinzón, A., Pritchard, L., Ramsahoye, B., Ren, Q., Restrepo, S., Roy, S., Sadanandom, A., Savidor, A., Schornack, S., Schwartz, D. C., Schumann, U. D., Schwessinger, B., Seyer, L., Sharpe, T., Silvar, C., Song, J., Studholme, D. J., Sykes, S., Thines, M., van de Vondervoort, P. J., Phuntumart, V., Wawra, S., Weide, R., Win, J., Young, C., Zhou, S., Fry, W., Meyers, B. C., van West, P., Ristaino, J., Govers, F., Birch, P. R., Whisson, S. C., Judelson, H. S., and Nusbaum, C. 2009. Genome sequence and analysis of the Irish potato famine pathogen Phytophthora infestans. Nature 461:393-398.

28. Haegeman, A., Jones, J., and Danchin, E. 2011. Horizontal gene transfer in nematodes: A catalyst for plant parasitism? Mol. Plant-Microbe Interact. 24:879-887.

29. Hamiduzzaman, M. M., Jakab, G., Barnavon, L., Neuhaus, J. M., and Mauch-Mani, B. 2005. $\beta$-Aminobutyric acid-induced resistance against downy mildew in grapevine acts through the potentiation of callose formation and jasmonic acid signaling. Mol. Plant-Microbe Interact. 18:819-829.

30. Iyer, G., and Chattoo, B. B. 2003. Purification and characterization of laccase from the rice blast fungus, Magnaporthe grisea. FEMS Microbiol. Lett. 227:121-126.

31. Jobic, C., Boisson, A. M., Gout, E., Rascle, C., Fèvre, M., Cotton, P., and Bligny, R. 2007. Metabolic processes and carbon nutrient exchanges between host and pathogen sustain the disease development during sunflower infection by Sclerotinia sclerotiorum. Planta 226: 251-265.

32. Kellner, H., Luis, P., and Buscot, F. 2007. Diversity of laccase-like multicopper oxidase genes in Morchellaceae: Identification of genes potentially involved in extracellular activities related to plant litter decay. FEMS Microbiol. Ecol. 61:153-163.

33. Le, S., and Gascuel, O. 2008. An improved general amino-acid replacement matrix. Mol. Biol. Evol. 25:1307-1320.

34. Marbach, I., Harel, E., and Mayer, A. M. 1985. Pectin, a second inducer for laccase production by Botrytis cinerea. Phytopathology 24:2559-2561.

35. Meng, S., Torto-Alalibo, T., Chibucos, M. C., Tyler, B. M., and Dean, R. A. 2009. Common processes in pathogenesis by fungal and oomycete plant pathogens, described with Gene Ontology terms. BMC Microbiol. 9(Suppl. 1):S7.

36. Newcombe, G., Stirling, B., McDonald, S., and Bradshaw, H. D., Jr. 2000. Melampsora $\times$ columbiana, a natural hybrid of $M$. medusae and $M$. occidentalis. Mycol. Res. 104:261-274.

37. Parrent, J. L., James, T. Y., Vasaitis, R., and Taylor, A. F. S. 2009. Friend or foe? Evolutionary history of glycoside hydrolase family 32 genes encoding for sucrolytic activity in fungi and its implications for plantfungal symbioses. BMC Evol. Biol. 9:148.

38. Pfaffl, M. W. 2001. A new mathematical model for relative quantification in real-time RT-PCR. Nucleic Acids Res. 29:2002-2007.

39. Polesani, M., Desario, F., Ferrarini, A., Zamboni, A., Pezzotti, M., Kortekamp, A., and Polverari, A. 2008. cDNA-AFLP analysis of plant and pathogen genes expressed in grapevine infected with Plasmopara viticola. BMC Genomics 9:142-153.

40. Reid, K. E., Olsson, N., Schlosser, J., Peng, F., and Lund, S. T. 2006. An optimized grapevine RNA isolation procedure and statistical determination of reference genes for real-time RT-PCR during berry development. BMC Plant Biol. 6:27.

41. Richards, T. A., Soanes, D. M., Jones, M. D. M., Vasieva, O., Leonard, G., Paszkiewicz, K., Foster, P. G., and Talbot, N. J. 2011. Horizontal gene transfer facilitated the evolution of plant parasitic mechanisms in the oomycetes. Proc. Natl. Acad. Sci. USA 108:15258-15263.

42. Richter, H., Pezet, R., Viret, O., and Gindro, K. 2006. Characterization of 3 new partial stilbene synthase genes out of over 20 expressed in Vitis vinifera during the interaction with Plasmopara viticola. Physiol. Mol. Plant Pathol. 67:248-260.

43. Rigling, D., and Van Alfen, N. K. 1993. Extra- and intracellular laccases of the chestnut blight fungus, Cryphonectria parasitica. Appl. Environ. Microbiol. 59:3634-3639.

44. Ruiz, E., and Ruffner, H. P. 2002. Immunodetection of Botrytis-specific invertase in infected grapes. J. Phytopathol. 150:76-85.

45. Schardl, C. L., and Craven, K. D. 2003. Interspecific hybridization in plant-associated fungi and oomycetes: A review. Mol. Ecol. 12:28612873.

46. Schmidlin, L., Poutaraud, A., Claudel, P., Mestre, P., Prado, E., SantosRosa, M., Wiedemann-Merdinoglu, S., Karst, F., Merdinoglu, D., and Hugueney, P. 2008. A stress-inducible resveratrol O-methyltransferase involved in the biosynthesis of pterostilbene in grapevine. Plant Physiol. 148:1630-1639.

47. Sekimoto, S., Beakes, G. W., Gachon, C. M. M., Muller, D. G., Kupper, F. C., and Honda, D. 2008. The development, ultrastructural cytology, and molecular phylogeny of the basal oomycete Eurychasma dicksonii, infecting the filamentous phaeophyte algae Ectocarpus siliculosus and Pylaiella littoralis. Protist 159:299-318.

48. Seong, K., Hou, Z., Tracy, M., Kistler, H. C., and Xu, J.-R. 2005. Random insertional mutagenesis identifies genes associated with virulence in the wheat scab fungus Fusarium graminearum. Phytopathology 95:744-750.

49. Sharma, M., Manoharlal, R., Puri, N., and Prasad, R. 2010. Antifungal curcumin induces reactive oxygen species and triggers an early apoptosis but prevents hyphae development by targeting the global repressor TUP1 in Candida albicans. Biosci. Rep. 30:391-404.

50. Soanes, D. M., Richards, T. A., and Talbot, N. J. 2007. Insights from sequencing fungal and oomycete genomes: What can we learn about plant disease and the evolution of pathogenicity? Plant Cell 19:3318-3326.

51. Thines, M., and Kamoun, S. 2010. Oomycete-plant coevolution: Recent advances and future prospects. Curr. Opin. Plant Biol. 13:427-433.

52. Torto, T. A., Rauser, L., and Kamoun, S. 2002. The pipg1 gene of the oomycete Phytophthora infestans encodes a fungal-like endopolygalacturonase. Curr. Genet. 40:385-390.

53. Trouvelot, S., Varnier, A., Allègre, M., Mercier, L., Baillieul, F., Arnould, C., Gianinazzi-Pearson, V., Klarzynski, O., Joubert, J., Pugin, A., and Daire, X. 2008. A beta-1,3 glucan sulfate induces resistance in grapevine against Plasmopara viticola through priming of defense responses, including HR-like cell death. Mol. Plant-Microbe Interact. 21:232-243.

54. Tucker, S. L., and Talbot, N. J. 2001. Surface attachment and prepenetration stage development by plant pathogenic fungi. Annu. Rev. Phytopathol. 39:385-417.

55. Voegele, R. T., Wirsel, S., Moll, U., Lechner, M., and Mendgen, K. 2006. Cloning and characterization of a novel invertase from the obligate biotroph Uromyces fabae and analysis of expression patterns of host and pathogen invertases in the course of infection. Mol. Plant-Microbe Interact. 19:625-634.

56. Werner, S., Steiner, U., Becher, R., Kortekamp, A., Zyprian, E., and Deising, H. B. 2002. Chitin synthesis during in planta growth and asexual propagation of the cellulosic oomycete and obligate biotrophic grapevine pathogen Plasmopara viticola. FEMS Microbiol. Lett. 208:169-173.

57. Whelan, S., and Goldman, N. 2001. A general empirical model of protein evolution derived from multiple protein families using a maximumlikelihood approach. Mol. Biol. Evol. 18:691-699.

58. Williamson, B., Tudzynski, B., Tudzynski, P., and van Kan, J. A. L. 2007. Pathogen profile-Botrytis cinerea: The cause of grey mould disease. Mol. Plant Pathol. 8:561-580.

59. Wu, C. H., Yan, H. Z., Liu, L. F., and Liou, R. F. 2008. Functional characterization of a gene family encoding polygalacturonases in Phytophthora parasitica. Mol. Plant-Microbe Interact. 21:480-489. 